\title{
CARACTERIZAÇÃO TECNOLÓGICA DE ALGUNS LITOTIPOS DO ESPÍRITO SANTO E DO NORDESTE E SUA APLICABILIDADE COMO ROCHAS ORNAMENTAIS
}

\author{
Glenda Aparecida Rodrigues de Oliveira' \\ Felisbela Maria da Costa Oliveira ' \\ Alinne Marianne Martins Araújo ' \\ Márcio Luiz de Siqueira Campos Barros '
}

\section{Resumo}

Características petrográficas e propriedades físicas e mecânicas de sete litotipos cinzas e amarelos do Espírito Santo (Cinza Andorinha, Cinza Corumbá, Arabesco e Santa Cecília) e do Nordeste (Cinza Pocinhos, Cinza Corumbá e Amarelo Ipanema) foram determinadas para avaliação do uso destas rochas como revestimentos, em função do ambiente e das solicitações. Os índices físicos, as resistências à compressão, à flexão e desgaste Amsler foram determinados a partir da NBR I5845/ABNT e NBR I2042/ABNT. As propriedades das rochas cinzas, independentemente de sua origem, são compatíveis com a NBR I5844, para rochas graníticas, e ASTM C 615 (americana). Entretanto, as amareladas apresentam valores muito próximos dos limites das normas: a cor amarela é indício de processos de alteração (oxidação, hidroxidação, hidratação), principalmente dos minerais ferromagnesianos, que diminuem as resistências, à compressão e à flexão, através de aumento de porosidade e absorção de água. A maioria das rochas apresentam valores adequados para uso como revestimento, com restrições para as amareladas, que necessitam de impermeabilização quando de seu uso em áreas úmidas. Palavras-chave: Rocha ornamental; Caracterização; Aplicação; Índices físicos.

\section{TECHNOLOGICAL CHARACTERIZATION OF SOME LITHOTYPES OF ESPÍRITO SANTO AND NORTHEAST AND THEIR APPLICATION AS ORNAMENTAL ROCKS}

\begin{abstract}
Petrographic features and physical and mechanical properties of seven rock types gray and yellow from Espirito Santo (Andorinha Gray, Corumbá Gray, Arabesco, and Santa Cecilia) and from the Northeast (Pocinhos Gray, Corumbá Gray and Yellow Ipanema) were determined to evaluate the use of these rocks as coatings, depending on the environment and applications. Physical indices, resistance to compression, to bending, and Amsler wear were determined byt NBR I5845/ABNT and NBR I2042/ABNT. The properties of the gray rocks, regardless of their origin, are compatible with NBR I5844, to granitic rocks, and ASTM C 615 (US). However, yellow rocks presented values very close to the limits of the standard: yellow color is a sign of change processes (oxidation, hidroxidation, hydration), mainly ferromagnesian minerals, which decrease the resistance to compressive and flexural strength, through increased porosity and water absorption. Most rocks have values suitable for use as a coating, with restrictions for yellow rocks, which require waterproofing when using it in humid areas. Keywords: Ornamental rock; Characterization; Application; Physical indices.
\end{abstract}

\section{INTRODUÇÃO}

O conhecimento das propriedades físico-mecânicas e das características químico-mineralógicas e petrográficas das rochas utilizadas como revestimento são fatores técnicos que podem afetar o preço do produto, as opções de uso e a valorização do material mediante as exigências do mercado. $O$ valor comercial da rocha é consequência direta das características técnicas da rocha ornamental, bem como das características estéticas

'Programa de Pós-graduação em Engenharia Mineral - PPGEMinas, Universidade Federal de Pernambuco - UFPE, Recife, PE, Brasil.

E-mail: glenda.oliveira@gmail.com

2176-1523 (C) 2016 Associação Brasileira de Metalurgia, Materiais e Mineração. Publicado pela ABM. Este é um artigo de acesso aberto distribuído sob os termos da licença Creative Commons CC BY-NC-ND (Attribution-NonCommercial-NoDerivs) - https:// creativecommons.org/licenses/by-nc-nd/4.0\%. 
(cor, textura e estrutura) e também do modismo do mercado. A utilização mais adequada para uma dada rocha deve ser aquela que apresente o valor técnico, estético e comercial mais elevado [I]. Entretanto, esse aspecto deve ser conjugado ao conhecimento das propriedades físicas e mecânicas para que a rocha escolhida tenha o desempenho esperado quando submetida às diversas solicitações de uso [2]. Para a definição destes parâmetros, recomenda-se que todos os materiais rochosos de ornamentação e revestimento sejam submetidos a ensaios de caracterização tecnológica. Estes ensaios servem para distinguir os campos de aplicação dos materiais e de seu comportamento frente às solicitações.

O objetivo deste trabalho é caracterizar, do ponto de vista tecnológico, rochas silicáticas, do Espírito Santo e Nordeste, de onde foram estudados sete diferentes tipos desses materiais utilizados como rocha ornamental, usados como revestimentos internos e externos, e determinar as correlações existentes entre suas características físicas e mecânicas e a aplicabilidade destes materiais como revestimentos. Para isto, são discutidos os resultados obtidos dos ensaios com relação aos limites propostos por órgãos regulamentadores, ABNT (brasileira) e ASTM (americana) para algumas características, tais como índices físicos, desgaste Amsler, resistência à compressão uniaxial, resistência à flexão, coeficiente de dilatação térmica linear, resistência ao impacto e congelamento/degelo.

\section{METODOLOGIA}

\section{I Materiais}

A seguir estão listados os materiais estudados e suas descrições petrográficas. A análise petrográfica é realizada através de exames macroscópicos de amostra in natura e microscópico das laminas delgadas das rochas, com espessura de $30 \mu \mathrm{m}$ ao microscópio de luz transmitida; descreve os minerais e seu arranjo textural; o tipo de rocha, o grau de alteração, o estado microfissural dos cristais, sua granulação e textura, e outras características que possam influenciar na durabilidade da rocha.

\section{I.I Cinza Corumbá, Paraíba}

Textura equigranular de granulação fina a média, tamanho médio dos cristais de 0,5 a I, $0 \mathrm{~cm}$, compacta, cor predominante cinza escuro devido à presença de biotita, presença de feldspatos alcalinos, sem foliação aparente. A rocha é definida por um agregado fino de cristais de quartzo e feldspatos (oligoclásio) imbricados com predominância de quartzo, com esporádica presença de ripas muscovíticas de diminutas. Esse conjunto é agregado por uma matriz muito fina caracterizada por um processo de silicificação micro cristalina. Sem fissuras ou fraturamento (Ver Tabela I e Figura I).

Tabela I. Composição mineralógica do Cinza Corumbá (PB), Cinza Pocinhos (PB), Cinza Corumbá (ES) e Cinza Andorinha (ES)

\begin{tabular}{lcccc}
\hline \multirow{2}{*}{ Composição Mineralógica } & \multicolumn{4}{c}{ Rochas } \\
\cline { 2 - 5 } & Cinza Corumbá, PB & Cinza Pocinhos, PB & Cinza Corumbá, ES & Cinza Andorinha, ES \\
\hline Quartzo & $50 \%$ & $25 \%$ & $18 \%$ & $18 \%$ \\
Plagioclásio (oligoclásio) & $38 \%$ & $40 \%$ & $25 \%$ & $31 \%$ \\
Biotita & $7 \%$ & $5 \%$ & $18 \%$ & - \\
Microclinio & - & $15 \%$ & - & - \\
Hornblenda & - & $5 \%$ & - & - \\
Titanita & - & $<5 \%$ & $36 \%$ & $35 \%$ \\
K-feldspato & - & - & $3 \%$ & $6 \%$ \\
Acessórios & $5 \%$ & $<5 \%$ & & \\
\hline
\end{tabular}
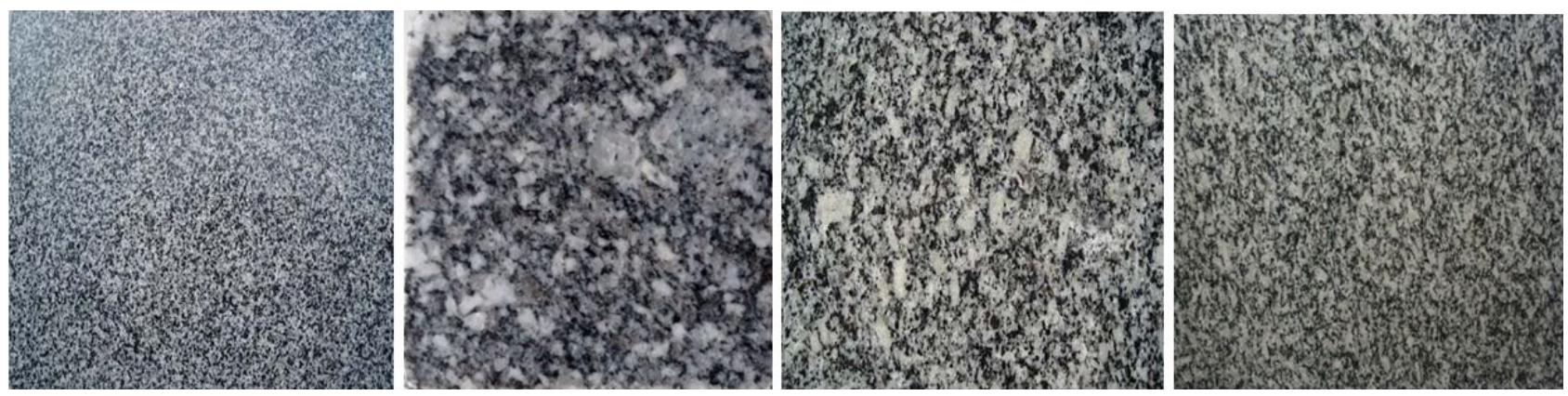

Figura I. Aspectos visuais do Cinza Corumbá (PB), Cinza Pocinhos (PB), Cinza Corumbá (ES) e Cinza Andorinha (ES), respectivamente, da esquerda para a direita. 


\subsubsection{Cinza Pocinhos, Paraíba}

Coloração cinza com pontos brancos e pretos. Rocha metamórfica com estrutura gnáissica e textura porfiroblástica/granolepidoblástica inequigranular de granulação fina a média, predominante média, variando entre $0,3 \mathrm{~mm}$ e 2,6 mm. Microclínio ocorre como porfiroblasto, podendo atingir proporções centimétricas. Microfissuras fraco a moderado. Micro fissuramento intragranular e intergranular em quartzo e feldspatos. Preenchimento por muscovita, sericita e, mais raramente, carbonato. Moderada alteração hidrotermal evidenciada pela turvação de feldspatos por sericita (Ver Tabela I e Figura I).

\subsubsection{Cinza Corumbá, Espírito Santo}

Rocha de composição monzogranítica, cor cinza, textura fanerítica inequigranular a porfirítica média a grossa ( $2 \mathrm{~mm}$ a $20 \mathrm{~mm}$ ), com destaque para cristais de K-feldspato branco acinzentado, que definem uma orientação na rocha. Os minerais essenciais são K-Feldspato, plagioclásio oligoclásio, biotita e quartzo. Os acessórios são titanita e zircão, e opacos (pirita) encontrados na rocha sob a forma de raras pontuações douradas. A rocha apresentou baixo grau de alteração e baixo micro fissuramento (Ver Tabela I e Figura I).

\section{I.4 Cinza Andorinha, Espírito Santo}

Composição monzogranítica e textura fanerítica equigranular fina a média, com cristais inferiores a $3 \mathrm{~mm}$. Os minerais essenciais são K-Feldspato, de cor acinzentada, com no máximo $3 \mathrm{~mm}$; ocorre também como aglomerados de dimensões de $5 \mathrm{~mm}$ juntamente com a magnetita formando pontuações pretas que se destacam entre os minerais acinzentados da rocha; plagioclásio, de cor esbranquiçada, inferiores a $1 \mathrm{~mm}$; quartzo, cristais xenomórficos cinza. Titanita e zircão ocorrem como acessórios, marrons, e dimensões inferiores a $1 \mathrm{~mm}$. A rocha apresentou baixo grau de alteração e baixo micro fissuramento (Ver Tabela I e Figura I).

\subsubsection{Amarelo Ipanema, Pernambuco}

Rocha isotrópica, de cor clara com tonalidade dominante róseo-pálida a levemente amarelada com pontuações pretas. É constituída de: feldspatos esbranquiçados, róseos pálidos, quartzo e pontuações de biotita. Os agregados de feldspato permitem identificar a textura heterogranular fanerítica. Identificaram-se plagioclásio albítico, K-feldspato, quartzo, e biotita. A ocorrência de defeitos (trincas, veios e xenólitos) é pouco comum [3] (Ver Tabela 2 e Figura 2).

\subsubsection{Amarelo Arabesco, Espírito Santo}

Apresenta textura fanerítica grossa, estrutura gnáissica, localmente porfiróide a porfiroblástica, inequigranular, granulação média a grossa (I-6 mm), com pouco quartzo, contrastando com muitos feldspatos, mica escura e granada. Os indivíduos ou agregados minerais possuem dimensões variáveis desde sub a supracentimétricos, mas sem grandes contrastes. Alterabilidade fraca a moderada e fissuramento

Tabela 2. Composição mineralógica do Amarelo Ipanema (PE), Amarelo Arabesco (ES) e Amarelo Santa Cecília (ES)

\begin{tabular}{lccc}
\hline \multirow{2}{*}{ Composição Mineralógica } & \multicolumn{2}{c}{ Rochas } & Amarelo Santa Cecília \\
\cline { 2 - 4 } & Amarelo Ipanema, PE & Amarelo Arabesco, ES & $9 \%$ \\
Quartzo & $5 \%$ & $4 \%$ & $66 \%$ \\
Plagioclásio albítico & $65 \%$ & $74 \%$ & $8 \%$ \\
Biotita & $5 \%$ & $3 \%$ & $10 \%$ \\
Granada & - & - & $4 \%$ \\
K-feldspato & $25 \%$ & $15 \%$ & $3 \%$ \\
Acessórios & - & $4 \%$ & \\
\hline
\end{tabular}
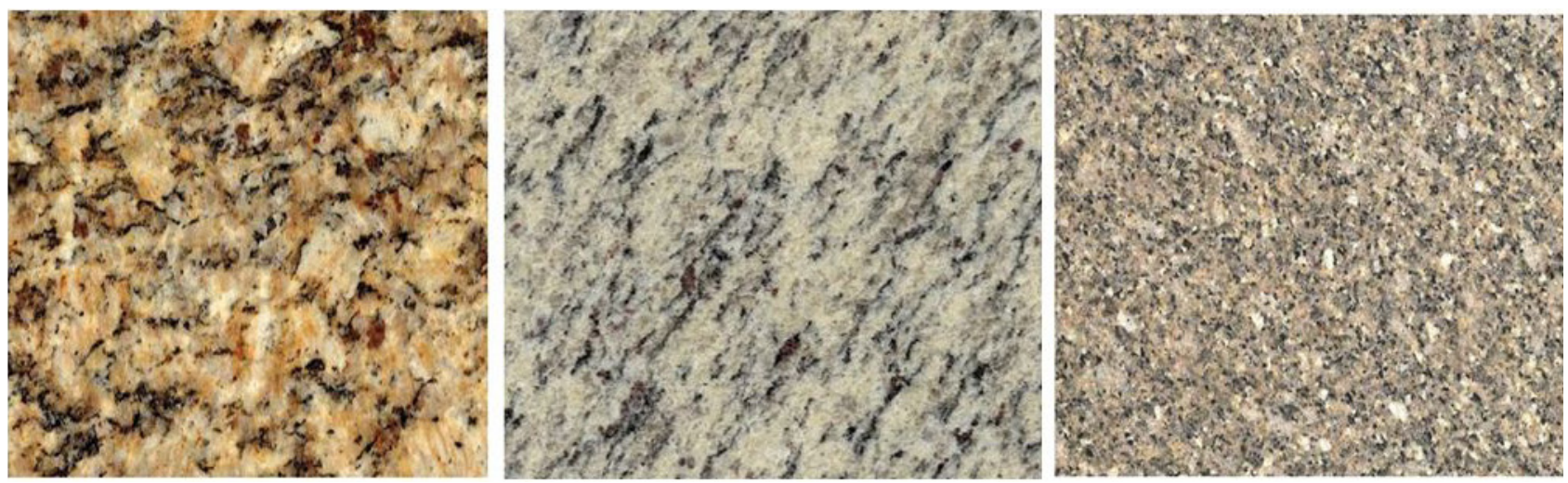

Figura 2. Aspectos visuais do Amarelo Ipanema (PE), Amarelo Arabesco (ES) e Amarelo Santa Cecília (ES), respectivamente, da esquerda para a direita. 
moderado a forte. Identificaram-se plagioclásio albítico, quartzo, K-feldspato e dentre os acessórios, biotita, sillimanita, granada, zircão e apatita (Ver Tabela 2 e Figura 2).

\section{I.7 Amarelo Santa Cecília}

Textura gnáissico-xistosa, granulação média a grossa (3- $10 \mathrm{~mm}$ ); os essenciais quartzo e feldspatos e o acessório granada exibem textura porfiróide e porfiroblástica que contrastam com a granulação dos acessórios micáceos. As formas sigmoidais são realçadas pela mica escura, preta a marrom, bordejando os feldspatos. Alterabilidade fraca a moderada e fissuramento moderado a forte (Ver Tabela 2 e Figura 2).

\subsection{Ensaios de Caracterização Tecnológica}

Segundo Frascá [2], o principal objetivo da realização de ensaios tecnológicos é a obtenção de parâmetros físicos e mecânicos que permitam a qualificação da rocha para uso em edificações (revestimentos, degraus, bancadas, móveis, monumentos).

$\mathrm{Na}$ Tabela 3, abaixo, estão listados os ensaios de caracterização tecnológica realizados e as respectivas normas que descrevem os procedimentos executados.

Tabela 3. Ensaios para caracterização dos litotipos

\begin{tabular}{|c|c|}
\hline \multirow{9}{*}{$\begin{array}{c}\text { ABNT NBR } \\
\text { I } 5845 \text { [8] }\end{array}$} & Análise petrográfica - Anexo A \\
\hline & Densidade aparente - Anexo B \\
\hline & Porosidade aparente - Anexo B \\
\hline & Absorção d'água - Anexo B \\
\hline & Coeficiente de dilatação térmica linear - Anexo C \\
\hline & Resistência ao congelamento e degelo - Anexo D \\
\hline & Resistência à compressão uniaxial - Anexo $E$ \\
\hline & Módulo de ruptura (flexão por três pontos) - Anexo $\mathrm{F}$ \\
\hline & Resistência ao impacto de corpo duro - Anexo H \\
\hline $\begin{array}{c}\text { ABNT NBR } \\
\text { I } 2042[9]\end{array}$ & Resistência ao desgaste \\
\hline
\end{tabular}

\section{RESULTADOS E DISCUSSÕES}

\section{I Índices Físicos}

A Tabela 4 mostra os resultados dos índices físicos das rochas estudadas. Todas apresentam densidade aparente superior à especificada seja pela norma americana ASTM C-6I5 $\left(\geq 2560 \mathrm{Kg} / \mathrm{m}^{3}\right)$ [4], seja pela norma NBR I $5844 \mathrm{da}$ ABNT $\left(>2550 \mathrm{~kg} / \mathrm{m}^{3}\right)$ [5], referente a rochas silicáticas. Com relação à porosidade e absorção aparentes, os granitos Cinza Corumbá PB, Arabesco ES e Santa Cecília ES apresentaram valores acima do sugerido pela NBR 15844 [5]. Valores de porosidade elevada podem indicar a existência de poros intercomunicantes; por conseguinte, maior será a absorção d'água da rocha e provavelmente menor a sua resistência mecânica. Portanto, porosidade e absorção d'água elevadas indicam a necessidade de impermeabilização das placas pétreas quando em aplicações em ambientes úmidos Os valores de porosidade e absorção aparentes do litotipo Amarelo Ipanema PE, apesar de atender à NBR I5844 [5] são muito próximos desses limites.

Sabe-se que a densidade das rochas varia inversamente à porosidade e à absorção e diretamente com a resistência. Valores elevados de densidade indicam baixos valores de porosidade e absorção e alta resistência à compressão. Quanto menos vazios, mais densa é a rocha e, por conseguinte, mais resistente ela será. Assim, os resultados listados na Tabela 4 indicam que os granitos Cinza Pocinhos PB, Corumbá ES e Andorinha ES e o Amarelo Ipanema PE podem ser usados sem restrição em revestimentos externos e em ambientes úmidos como balcões e pias de cozinhas e banheiros e lavabos, devido à baixa porosidade e absorção. Entretanto, segundo Kalix [6], devem-se observar a composição mineralógica, a existência ou não de microfissuras, relações de contato entre os grãos minerais, granulação, aspectos estruturais, entre outras, pois, influenciam diretamente a porosidade, densidade e absorção d'água da rocha sendo esses elementos extremamente importantes na avaliação da durabilidade e da resistência mecânica ao longo do tempo.

Tabela 4. Índices físicos

\begin{tabular}{lccc}
\hline \multicolumn{1}{c}{ Litotipos } & \multicolumn{3}{c}{ Índices físicos } \\
\cline { 2 - 4 } & Densidade Aparente $\mathbf{( K g / \mathbf { m } ^ { 3 } )}$ & Porosidade aparente (\%) & Absorção d'água (\%) \\
\hline Cinza Corumbá PB & 2638 & 1,114 & 0,497 \\
Cinza Pocinhos PB & 2710 & 0,408 & $0,15 \mathrm{I}$ \\
Cinza Corumbá ES & 2673 & 0,930 & 0,350 \\
Cinza Andorinha ES & 2703 & 0,830 & 0,310 \\
Amarelo Ipanema PE & 2623 & 0,944 & 0,358 \\
Arabesco ES & 2730 & 1,984 & 0,718 \\
Santa Cecília ES & 2637 & 1,487 & 0,567 \\
Normas & & & $\leq 0,40$ \\
NBR I5844 & $>2550$ & $\leq 1,00$ & 0,40 \\
ASTM C 6I5 & $>2560$ & Não especificado & \\
\hline
\end{tabular}




\subsection{Propriedades Mecânicas}

A Tabela 5 apresenta os valores das propriedades mecânicas ensaiadas e também os limites estabelecidos pelas normas brasileira e americana.

De acordo com Frascá [7], o ensaio de resistência à compressão determina a tensão $(\mathrm{MPa})$ que provoca a ruptura da rocha quando submetida a esforços compressivos. Sua finalidade é avaliar a resistência da rocha quando utilizada como elemento estrutural e obter um parâmetro indicativo de sua integridade física. Os granitos Cinza Pocinhos PE, Cinza Corumbá ES, Cinza Andorinha ES, apresentam considerável resistência à compressão uniaxial, fato compatível com seus índices físicos. Portanto, estes litotipos podem ser aplicados sem restrição em situações onde haja solicitações à compressão e, por conseguinte, em revestimentos internos e externos, pisos e paredes, áreas secas ou molhadas; contudo, apesar de elevados valores de resistência à compressão indicarem rochas de boa qualidade, densas, (baixas porosidade e absorção d'água) sua composição mineralógica e textura devem ser levadas em consideração quando da decisão sobre sua aplicação principalmente em áreas externas e submetidas à umidade. Quanto aos granitos amarelos, as resistências são inferiores àquelas dos cinzas, mas ainda superior a $100 \mathrm{Mpa}$, o que pode garantir bom desempenho quando de sua utilização; quanto ao granito Santa Cecília ES, a resistência à compressão é inferior àquela da NBR 15844 [5], portanto, deve ser usado com restrições, notadamente em áreas úmidas como banheiros, cozinhas, lavabos e áreas externas. Quando se considera a ASTM C6I5, todas as amostras amarelas ficaram abaixo do limite.

O granito Cinza Corumbá PB apresenta a maior resistência à compressão $(244,67 \mathrm{MPa})$ entre todas as rochas. Entretanto a absorção d'água e porosidade estão acima do recomendado pela NBR. Este fato pode ser explicado pelo elevado teor de quartzo (50\%) presente em sua composição: o quartzo apresenta microfissuramento decorrente da condição natural de fratura, o que se traduz em maior porosidade e absorção d'água e ainda rochas mais silicificadas apresentam maior resistência à compressão. Assim este litotipo pode ser aplicado em ambientes internos, em pisos, paredes, nas áreas sociais; contudo, não se recomenda aplicá-lo em cozinhas e em ambientes externos em virtude da porosidade elevada e absorção d'água acima do limite.

A resistência a flexão dos granitos cinzas variaram entre 10, $18 \mathrm{MPa}$ e $21,73 \mathrm{MPa}$, enquanto dos granitos amarelos ficaram entre 7,59 MPa e I4, I I MPa. Comparados aos limites da NBR 15844 e ASTM C6I5, são bastante satisfatórios exceto para os litotipos amarelos Arabesco ES e Santa Cecília ES. Portanto, os granitos Cinza Pocinhos PB, Cinza Corumbá ES, Cinza Andorinha ES podem ser usados em revestimentos externos aplicados com "inserts" metálicos constituindo as fachadas ventiladas ou aeradas. O Cinza Corumbá $\mathrm{PB}$, apesar de exibir alta resistência à flexão, também apresenta porosidade elevada o que o contraindica para aplicações em áreas externas como fachadas. Quanto aos granitos amarelos, apenas o Amarelo Ipanema mostrou ser satisfatório quanto à resistência à flexão; entretanto, devido à sua coloração amarelada, indicativa de processos de alteração de seus minerais, pode ser apenas aplicado em ambientes internos, onde não haja umidade excessiva, a fim de evitar ainda mais deterioração. Os granitos Arabesco e Santa Cecília apresentam baixa resistência à flexão, contraindicados, portanto, em fachadas aeradas e ventiladas e áreas úmidas e indicados como revestimento em ambientes internos.

Segundo Frascá [2], o ensaio de desgaste Amsler determina a resistência ao desgaste do material pétreo frente ao tráfego de pessoas e/ou veículos. Os resultados do desgaste Amsler dos vários litotipos estão descritos na Tabela 5, comparados apenas com a especificação da NBR I5844, já que a norma ASTM C6I 5 não especifica este limite. As resistências à abrasão dos granitos cinzas ficaram bem próximas do valor da NBR, o que indica a utilização destas rochas em ambientes de pisoteio moderado. Apenas - Cinza Corumbá PB se mostrou bastante resistente ao desgaste abrasivo o que é explicado pelo elevado teor de quartzo (50\%), apropriado, portanto, para ambientes de

Tabela 5. Resultados dos ensaios mecânicos

\begin{tabular}{lcccc}
\hline \multicolumn{1}{c}{ Litotipo } & $\begin{array}{c}\text { Resistência à } \\
\text { compressão (MPa) }\end{array}$ & $\begin{array}{c}\text { Módulo de ruptura } \\
\text { (flexão) }(\mathbf{M P a})\end{array}$ & $\begin{array}{c}\text { Resistência a impacto } \\
\text { de corpo duro }(\mathbf{m})\end{array}$ & $\begin{array}{c}\text { Desgaste Amsler } \\
\mathbf{1 0 0 0 \mathbf { m }}(\mathbf{m m} / \mathbf{1 0 0 0} \mathbf{m})\end{array}$ \\
\hline Cinza Corumbá PB & 244,67 & 21,73 & $*$ & 0,398 \\
Cinza Pocinhos PB & 140,9 & 13,96 & $*$ & 1,17 \\
Cinza Corumbá ES & 130,2 & 10,18 & $*$ & 1,00 \\
Cinza Andorinha ES & 151,5 & 12,63 & $*, 90$ & 1,00 \\
Amarelo Ipanema & 105,42 & 14,11 & 0,35 & 1,60 \\
Arabesco & 106,52 & 7,59 & 0,40 & 0,794 \\
Santa Cecília & 86,42 & 7,61 & & 0,82 \\
Normas & & & $>0,30$ & $<1,00$ \\
NBR I5844 & $>100,00$ & $>10,00$ & Não especificado & Não especificado \\
ASTM C 6I5 & $>131,00$ & $>10,34$ & & \\
\hline
\end{tabular}

* Não determinado. 
pisoteio intenso. Em relação aos granitos amarelos, o desgaste abrasivo do Arabesco e Santa Cecília, que apresentam em sua composição minerais de dureza elevada como a granada e o zircão ( $D=6$ a 7,5), ficaram abaixo de $I, 00 \mathrm{~mm}$; o que não ocorre o Amarelo Ipanema cujo desgaste ficou acima do normatizado. Consequentemente, este último deve ser aplicado apenas em pisos onde o tráfego de pessoas seja moderado como em residências, e os granitos Amarelos Arabesco e Santa Cecília apropriados para níveis de pisoteio mais intensos como áreas de grande circulação de pessoas, desde que o ambiente não seja úmido por causa da presença das granadas, mineral ferromagnesiano.

Por questões técnicas, os ensaios de resistência a impacto de corpo duro foram realizados apenas nos granitos amarelos. O objetivo deste ensaio é simular a queda de objetos em um piso e observar os danos causados. Utiliza-se da energia potencial gravitacional, que é a energia acumulada no corpo por causa da ação da gravidade, e é expressa pelo produto de sua massa, aceleração da gravidade e altura em relação ao referencial. Todos os granitos amarelos apresentaram valores satisfatórios. O Amarelo Ipanema apresentou a maior resistência a impacto de corpo duro, explicada pelo menor tamanho dos seus grãos que possibilitam uma maior coesão e imbricamento dos minerais; pode ser utilizado sem restrições como revestimento vertical em locais onde haja impactos como em saguões de aeroportos, supermercados, lojas, etc. As resistências ao impacto dos granitos Arabesco e Santa Cecília são próximas mas bem inferiores à do Amarelo Ipanema. Isto se deve, muito provavelmente, à foliação e tamanho de cristais (supramilimétrico) presentes nestas rochas, com capacidade de absorção de impacto limitada em função da foliação apresentada.

A resistência ao congelamento e degelo mede a variação deste parâmetro quando a rocha é submetida a vários ciclos de congelamento e descongelamento no estado saturado. Observa-se, na Figura 3, que os resultados estão mais próximos da NBR 15844 [5] pois este limite foi proposto a partir de ensaios realizados em rochas brasileiras, de clima tropical, ao contrário dos valores fixados pela ASTM [8], que tem como base as rochas do continente norte-americano, de clima subtropical.

Os vários ciclos de congelamento/degelo provocaram no granito Cinza Pocinhos PB, perda de resistência de 13\% na condição paralela, e $8,67 \%$ na condição perpendicular: a presença de biotita e a fina textura podem ter colaborado para esta queda de resistência significativa nas duas direções.

Adicionalmente detectou-se que o número de ciclos determinado pela norma é insuficiente, pois para rochas Cinza Corumbá ES e Cinza Andorinha ES que têm baixa porosidade, os 25 ciclos foram insuficientes para causar perdas significativas na resistência, fato provavelmente relacionado ao baixo microfissuramento e pequena alterabilidade dos minerais.

Como as rochas se dilatam e se comprimem, quando submetidas a alterações contínuas e bruscas de temperatura, é importante caracterizar a reação do material rochoso a este parâmetro, o coeficiente de dilatação térmica linear, pois ele definirá os espaçamentos que deverão ser utilizados durante os procedimentos de assentamento. De acordo com a NBR I 5844 [5], o valor máximo de coeficiente de dilatação térmica para granitos ornamentais é de $8,0 \times 10^{-3} \mathrm{~mm} / \mathrm{m}^{\circ} \mathrm{C}$.

Com base nos valores apresentados na Figura 4 a seguir, percebe-se que litotipos estudados apresentaram valores de dilatação abaixo do valor máximo, considerado. Assim, essas rochas ser utilizadas tanto na situação de pisos em ambientes internos e externos, bem como em paredes e fachadas convencionais e ventiladas.

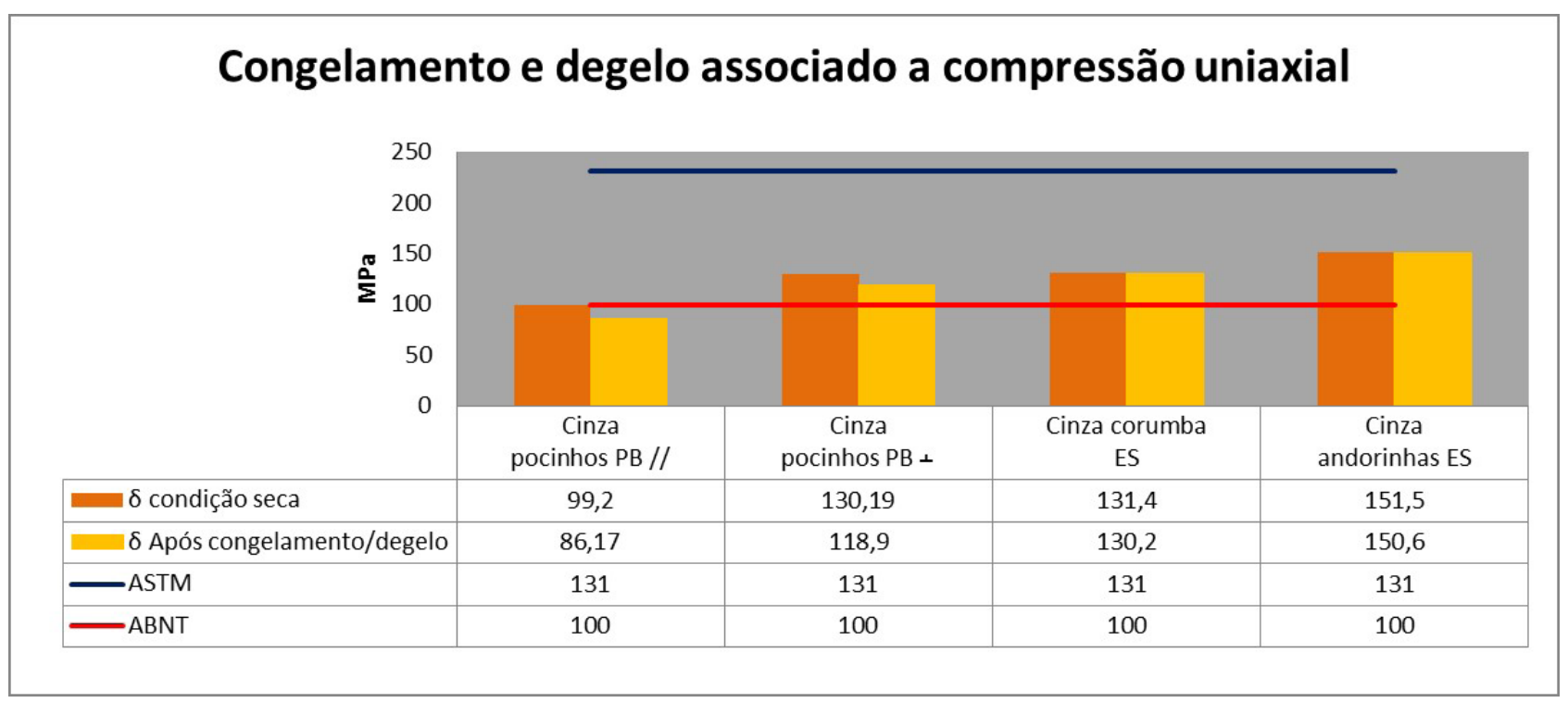

Figura 3. Congelamento e degelo associado à compressão uniaxial. 


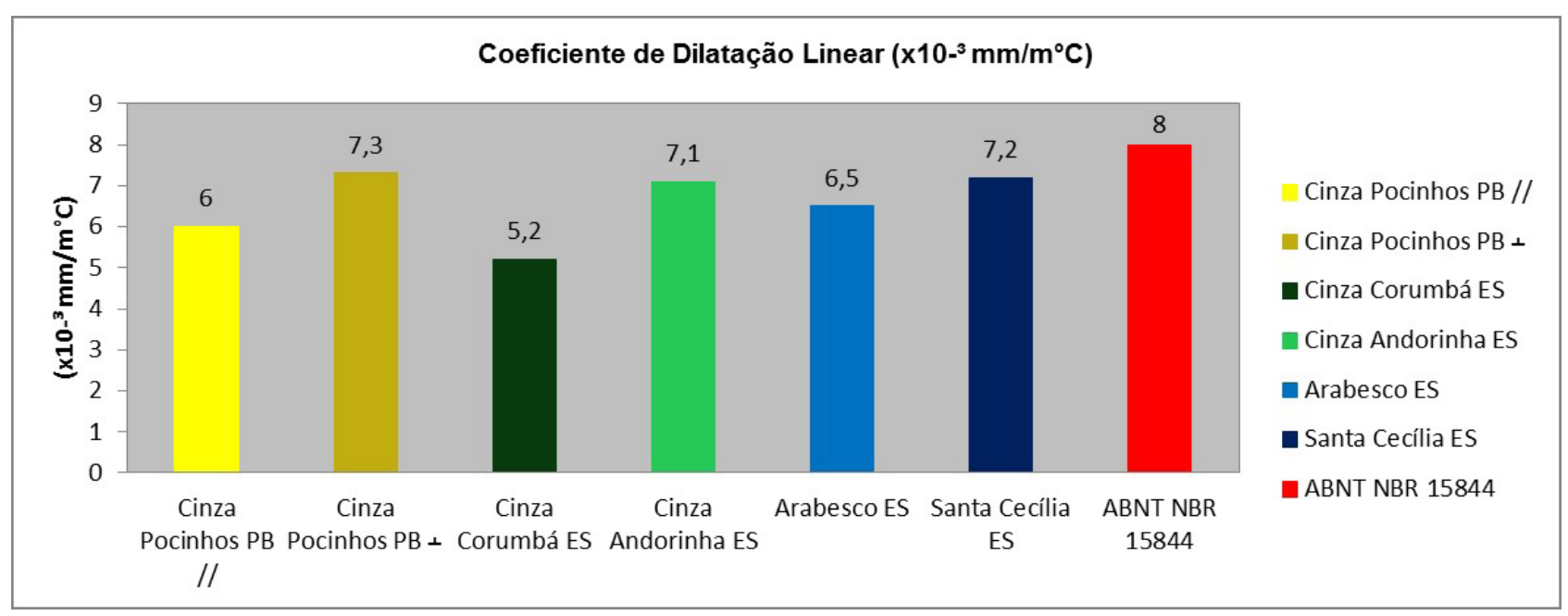

Figura 4. Coeficiente de Dilatação Linear.

\section{CONCLUSÕES}

Todos os litotipos estudados apresentaram valores de densidade aparente satisfatórios conforme a NBR I 5844 e ASTM C6 I5. Em relação à porosidade e absorção d'água aparentes, o Cinza Corumbá PB, e os granitos amarelos Arabesco e Santa Cecília apresentaram resultados elevados. Recomenda-se, pois, a impermeabilização destes materiais para aplicações em ambientes úmidos e áreas externas.

Quanto à resistência à compressão uniaxial, o Cinza Corumbá PB apresenta valor bastante elevado em relação às normas NBR 15844 e ASTM C6I5, o que é explicado pelo elevado teor em quartzo: rochas mais silicificadas apresentam maiores resistências. O Amarelo Santa Cecília ES apresenta um desempenho abaixo do recomendado pelas duas normas, explicado pelo grau de alteração, causado por processos de oxidação, hidroxidação e hidratação, que é indicado pela coloração amarelada desta rocha.

O granito Cinza Pocinhos PB foi aquele que mais apresentou perda de resistência quando submetido aos ciclos de congelamento/degelo. O Cinza Corumbá e Cinza Andorinha, ambos do Espírito Santo, tiveram perda de resistência muito baixa. Podem, portanto, ser exportados para uso em ambientes onde há congelamento da água, em invernos rigorosos como Europa, América do Norte e Japão.
Quanto à resistência à flexão, o Cinza Corumbá PB apresenta resultado elevado; a resistência à flexão (tração) é cerca de $10 \%$ do valor de resistência à compressão, o que explica o elevado valor para este litotipo. Pode ser usado como revestimento com "inserts" metálicos, pois suporta bem a ação dos ventos. No entanto, os granitos Arabesco e Santa Cecília apresentam baixa resistência o que contraindica a aplicação em fachadas aeradas ou ventiladas.

O Cinza Corumbá PB apresenta elevada resistência ao desgaste abrasivo, o que está relacionado ao alto teor de quartzo, podendo ser usado em ambientes de grande pisoteio. Já o Cinza Pocinhos PB e o Amarelo Ipanema PE tiveram o resultado acima do especificado na norma NBR 15844 [5]. Assim estes materiais devem ser usados com restrição quando se trata de revestimentos de pisos.

O resultado do ensaio de resistência ao impacto de corpo duro do granito Amarelo Ipanema PE indica uma resistência mediana a alta, podendo ser utilizada como rocha ornamental em revestimentos de paredes e pisos onde há possibilidade de choques como em aeroportos, supermercados e centros comerciais.

Os coeficientes de dilatação térmica de todos os litotipos são menores que o valor da NBR I5844 [5]: podem, pois, ser utilizados em pisos em ambientes internos e externos, bem como em paredes e fachadas convencionais e ventiladas.

\section{REFERÊNCIAS}

I Moura AC, Grade J, Ramos JMF, Moreira AD, Gomes L. Granitos e rochas similares de Portugal. Lisboa: IGM Editora; 2000. 179 p.

2 Frascá MHBO. Curso: qualificação de rochas ornamentais e para revestimento de edificações: caracterização tecnológica e ensaios de alterabilidade. In: Anais do I Congresso Brasileiro de Rochas Ornamentais e II Seminário de Rochas Ornamentais do Nordeste; 200I; Salvador, Bahia. 200I. p. I28-I35.

3 Souza VC. Diagnóstico do setor de rochas ornamentais e de revestimento do estado de Pernambuco [dissertação de mestrado]. Recife: Universidade Federal de Pernambuco; 2008. 167 p. 
Oliveira et al.

4 American Society for Testing and Materials - ASTM. ASTM C 6I5: standard specification for granite dimension stone. West Conshohocken: ASTM; 2011.

5 Associação Brasileira de Normas Técnicas - ABNT. ABNT NBR I5844. Rochas para revestimentos, requisitos para granitos. Rio de Janeiro: ABNT; 2010.

6 Kalix TMF. Estudos de caracterização tecnológica com ênfase em alterabilidade dos tipos comerciais do granito Marrom Imperial [dissertação de mestrado]. Recife: Universidade Federal de Pernambuco; 201 I.

7 Frascá MHBO. Estudos experimentais de alterabilidade acelerada de rochas graníticas para revestimento [tese de doutorado]. Universidade de São Paulo; 2003.

8 Associação Brasileira de Normas Técnicas - ABNT. ABNT NBR 15845: rochas para revestimento: métodos de ensaio. Rio de Janeiro: ABNT; 2010.

9 Associação Brasileira de Normas Técnicas - ABNT. ABNT NBR I2042: materiais inorgânicos: determinação do desgaste por abrasão. Rio de Janeiro: ABNT; 1992.

Recebido em: II Jul. 2016

Aceito em: 13 Out. 2016 